\title{
RAILWAY SUPERSTRUCTURE FOR HIGH-SPEED RAILS
}

\author{
LukÁŠ TÝFA $^{a, *}$, JAN KRUntorÁD ${ }^{a}$, Ondřej TOMASChKO ${ }^{b}$ \\ ${ }^{a}$ Czech Technical University in Prague, Faculty of Transportation Sciences, Department of Transportation \\ Systems, Horská 3, 12803 Prague 2, Czech Republic \\ ${ }^{b}$ DB Projekt Stuttgart-Ulm GmbH, Räpplenstraße 17, 70191 Stuttgart, Germany \\ * corresponding author: tyfa@fd.cvut.cz
}

ABstRACT. The construction of the track is solved as a conventional (with track ballast) or as a
ballastless track (without track ballast). When deciding on the choice of the most suitable track design
for high-speed rail, it is necessary to emphasize that with increasing line speed, the requirements for
the quality of the track geometry increase, including the size of the deviations of individual geometric
parameters of the track from the projected values. When assessing the choice of track structure -
especially for high-speed rails - it is therefore necessary and correct to assess the total costs (investment
and operational) for a sufficiently long time. DB Netz AG's present experience with a ballastless track
since its first implementation in 1972 in Rheda station, for almost 50 years, shows that the required
lifetime of 60 years has its real justification. In addition, current research and development in the field
of ballastless track is moving towards extending the life of ballastless track well beyond this limit. The
paper is focused on the comparison a ballasted and ballastless track construction. It deals in more
detail with evaluation of the advantages and disadvantages of a ballastless track construction. The
main objective is to assess the use of ballastless track structure for the construction of high-speed lines.

KEYWORDS: Track construction, track structure, track ballast, ballastless track, high-speed rail, investment and operational costs.

\section{Ballastless Track Characteristics}

The construction of the track is solved as a conventional (with track ballast) or as a ballastless track (without track ballast). In conventional track construction, the ballast bed performs the function of transmitting force effects from the rail supports to the track substructure and serves to make the railway superstructure more elastic (attenuates dynamic forces from moving vehicles); at the same time, it resists the displacement of the track skeleton in the transverse and longitudinal direction, ensures the drainage of rainwater from the track and enables the directional and height adjustment of the track geometry. In the case of a ballastless track, the ballast bed is replaced by cement concrete or asphalt concrete, and thus the load transfer function of the rolling stock is taken over by the load-bearing concrete layer [1]. The missing elasticity of the ballast bed is replaced by additional elastic elements in the rail fastening, or in a loadbearing slab of a ballastless track (elastic layer for concreted transverse sleepers or slabs).

Ballastless track is used worldwide on all types of railways (included railway lines as well as city railways systems - trams systems and underground systems) and there are many types of this structure about concerning their manufacturers and suitability for use in particular, the ballastless track types suitable for urban railways with a cover that road vehicles can drive on, and the ballastless track types with the open superstructure (without the cover), which can be supplemented with various elements to eliminate the noise propagation (absorbers). Furthermore, specific types of a ballastless track can be divided according to the principle of rail mounting, according to the degree of use of prefabricated elements, and according to the system of construction and use of transverse sleepers [2]. The decision to use either the conventional track construction or the ballastless track applies not only to the railway superstructure but is also reflected in the requirements for the track substructure - when choosing a ballastless track, significantly higher demands are placed on its stability $[3]$.

When deciding on the choice of the most suitable track construction for high-speed rails, it is necessary to emphasize that with increasing line speed, the requirements for the quality of the track geometry increase, including the size of the deviations of individual geometric parameters of the track from the projected values. At the same time, a stable geometric position of the track with minimal deviation is a condition for smooth running of rolling stock, for low wear of the railway superstructure and wheels of vehicles, for low noise and vibration emissions. With the same track construction and at the same time increasing line speed, the costs of track maintenance and demand on possession activity increase. Track possessions are not only highly unattractive for railway carriers and their customers, but also reduce the railway operator's revenues from the railway use fee, and they are difficult in organizing and providing a 
high level of safety and require the deployment of costly track machinery with specially qualified personnel. Higher maintenance costs are negatively reflected in the overall economic evaluation of the construction work during its entire life, and frequent maintenance can paradoxically shorten the life of some materials (ballast bed).

\section{Advantages and Disadvantages OF A BALlastless TRACK}

Advantages of a ballastless track compared to a conventional track construction:

- Significantly lower maintenance requirements (only replacement of worn rails or rail fastening elements; no tamping, no gravel cleaning), and therefore very low operating costs, no operation disruption, and minimal track possession.

- Longer service life (stated at least 50 years, in Germany the internal regulation of DB Netz AG requires 60 years). During the planned lifetime of the ballastless track, the ballast bed in the conventional track structure is established 2-3 times, because simple maintenance is no longer effective, which means high costs and extensive track possessions with significant complications (see above).

- Lower construction height, which is a great advantage for track substructure - especially in tunnels it leads to a smaller stope, which significantly saves investment costs; and bridges can be designed with a lower construction height, which can be used for the easier design of track level or increase the bridge span (e.g. increase underpass height on the road). The lower construction height of the ballastless track can be used for additional line electrification in existing tunnels.

- A lower weight of the structure at a lower construction height, which is reflected in a lower load on track substructure (especially bridge structures).

- Smaller land take, as it is not necessary to widen the sub-ballast surface in the curve. Even with a maximum cant of $180 \mathrm{~mm}$, the sub-ballast surface has a constant width of $12.10 \mathrm{~m}$ at DB Netz AG (at a track-center distance of $4.50 \mathrm{~m}$ ).

- Possibility to use a higher cant and its deficiency, which allows the design of smaller curve radius for a given line speed, and thus facilitates the routing the track through the terrain. The smaller curve radius together with the constant width of the sub-ballast surface make the possibility to route a new highspeed rail parallelly with an existing motorway (e.g. high-speed rail Stuttgart - Ulm or Nürnberg - Ingolstadt), creating a single transport corridor. When designing a high-speed rail using ballastless track, which allows achieving the required line speed with smaller curve radius than the conventional track construction, and with high gradient, it is possible to achieve a reduction in the share of bridges and tunnels, which has a significant positive economic impact not only on investment costs but also on operational costs (significantly lower subsequent maintenance of the track).

- High transverse and longitudinal stability of the track, which is especially important for the stability of the continuous welded rail.

- In the event of an emergency, a more convenient escape route for passengers, which allows faster evacuation, which is essential for tunnels. However, it is still necessary to assess the possibility of driving the ballastless track by rescue and evacuation road vehicles. For example, in Germany, for this reason, special slabs must be laid between the rails. This adjustment of the conventional track construction with a rail bed would need the maintenance of the track geometry, removal, and re-laying of special slabs, which is uneconomical and time-consuming. It is not necessary to disassemble these special slabs for the ballastless track due to inspection of rail fastening, rail replacement, or rail grinding.

- Almost dust-free operation.

- Non-restricted use of eddy current brakes, which only applies if the track is used by vehicles equipped with these types of brakes.

- There is no risk of damage caused by flying gravel from the railway bed, during which the individual grains of ballast are sucked by passing rolling stock and thrown out of the track. More precisely, no additional measures are required in the track construction to prevent this dangerous phenomenon (sealing of gravel in the track bed). Flying gravel not only destroys rail vehicles, but also damages the entire structure of the railway superstructure (sleepers and rail fasteners are most often damaged, but the rails are also damaged).

- There is no need to use very harmful chemicals based on herbicides and pesticides to destroy vegetation in the track area.

Disadvantages of a ballastless track compared to a conventional track construction:

- Higher investment costs. The multiplicity varies significantly, especially according to countries and their different prices of raw material inputs, labour costs and machinery costs, as well as according to the scope of building of a ballastless track. In the conditions of the Czech Republic, the multiplicity is expected to be approximately at the level of two to three times the investment costs of a track with a ballast bed. However, in the construction of a new high-speed rail, the investment costs of railway superstructure rarely exceed $10 \%$ of the total costs, so the more expensive ballastless track will not increase the price of the whole construction many times over. Besides, experience from DB Netz AG's 


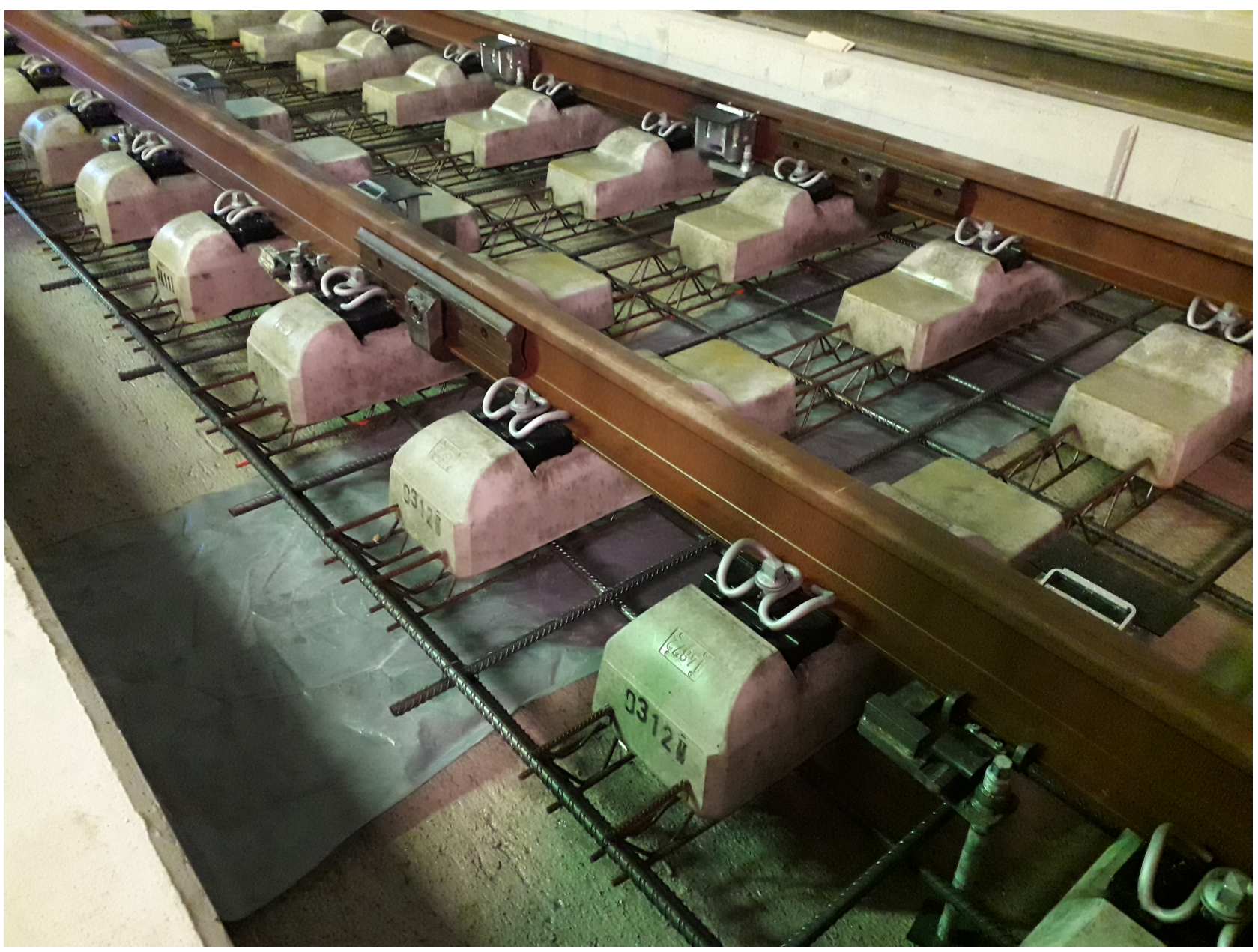

FiguRE 1. Ballastless track type RHEDA 2000 before casting (by concrete), photography author: DB Projekt Stuttgart-Ulm GmbH/Ondřej Tomaschko

investment projects shows that the cost of ballastless track construction in a tunnel is lower than the cost of building a conventional track structure with a ballast bed and with a sub-ballast vibration damping mat.

- Necessary high demands on the accuracy and quality of construction - but the same as with other cement concrete or asphalt concrete constructions. The track geometry cannot be significantly corrected, however, the ballastless track fastening systems are designed to allow the rail to be moved vertically and transversely in the unit order of a few tens of millimetres (e.g. Vossloh's 300 series rail fastening system allows additional height control $-4 /+56 \mathrm{~mm}$, exceptionally up to $-4 /+76 \mathrm{~mm}$, and directional control $\pm 16 \mathrm{~mm})$. Even with conventional track construction, it is not possible to significantly change its position (especially in the case of continuous welded rail).

- Slower construction, although currently even monolithic types of the ballastless track (e.g. type RHEDA 2000) are set up with the use of machine laying (finishers), when it is possible to achieve an output of up to $250 \mathrm{~m}$ of established track per day (in two shifts), or more precisely twice for the hydraulically bound layer under the top concrete slab (HGT). It is susceptible to track substructure stability (settlement), therefore its establishment on bridges and tunnels is simpler, thus it is more frequent (even with the use of other advantages mentioned above) - on the earthwork, multi-layer load-bearing systems are required. For example, in Germany, a permit for the construction of a ballastless track is issued only when the settlement of a maximum of $15 \mathrm{~mm}$ is confirmed from the performed measurements and subsequent calculations for the entire planned ballastless track service life, that means within 60 years.

- Higher noise emissions, which can be eliminated by adding elements of active noise protection (absorbers, rail damper, etc.); however, these elements increase investment and operating costs. High noise emissions from moving trains must also be solved in the conventional track construction - especially at very high speeds (from approx. $250 \mathrm{~km} / \mathrm{h}$ ) the dominant is aerodynamic noise, which intensity is influenced exclusively by the running train (depends on train speed, shape, and its external surfaces). 


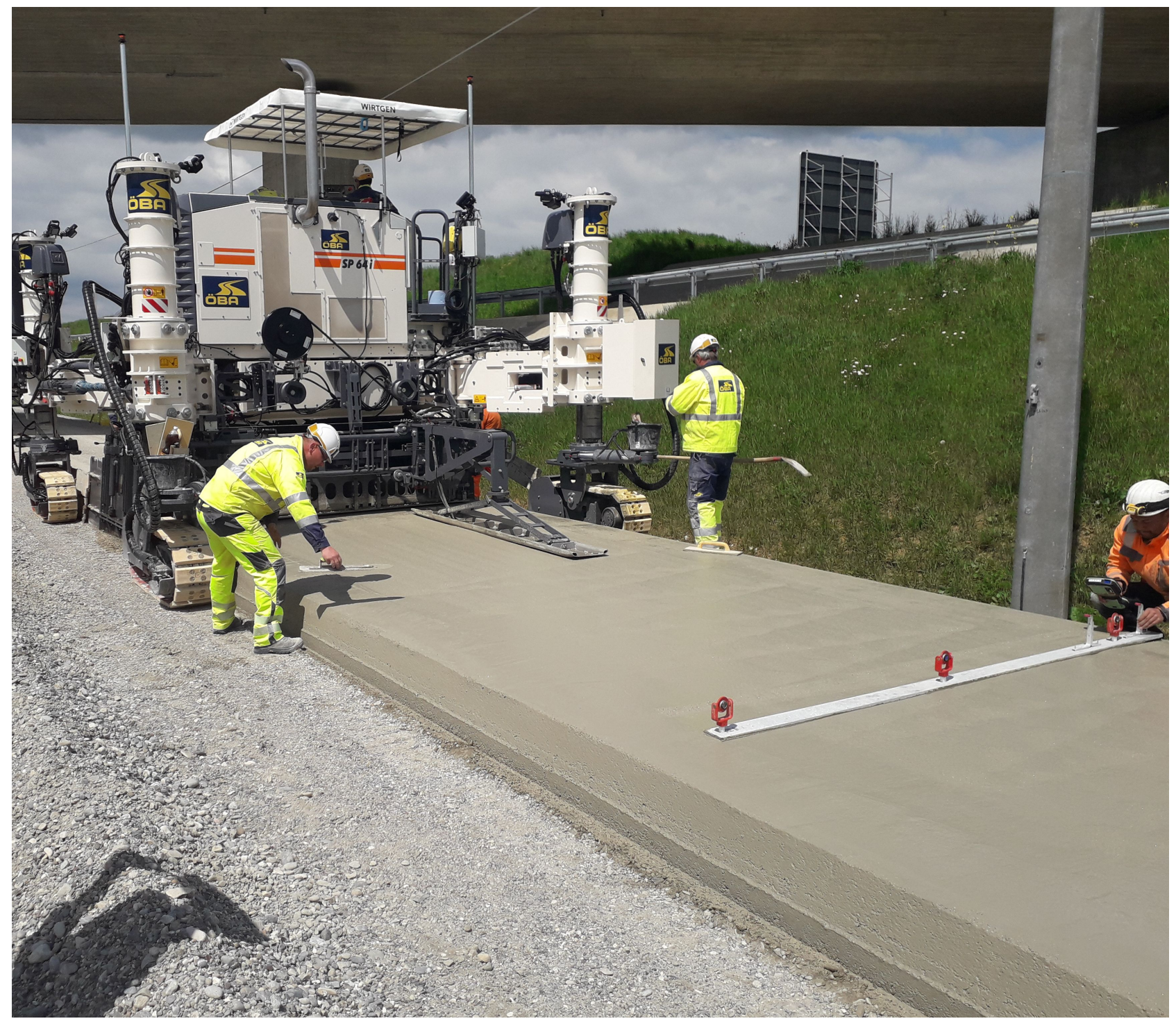

Figure 2. Machine laying by finisher of the hydraulically bound layer under the top concrete slab (HGT), Photography author: DB Projekt Stuttgart-Ulm GmbH/Ondřej Tomaschko

- In the event of structural failure (derailment, settlement of the foundation, etc.), extensive and expensive repairs are required. However, in the case of the consequences of train operation (derailment), it usually takes less time than removing vehicles and investigating an emergency on-site. Also, the ballastless track establishment includes the concept of its repair and rehabilitation. Most types of ballastless track structures can be put into temporary operation in a relatively short time after an extraordinary event or the occurrence of a defect, and the subsequent adjustment to the original state can then be carried out in the planned track possession.

- More time-consuming and financially demanding removal of its construction and subsequent recycling of the obtained material at the end of ballastless track service life.

\section{Other Factors Influencing the Decision on the Choice of Type of Railway Construction}

In addition to the requirement for a long service life and at the same time low maintenance costs, the track structure must be designed in such a way that it can easily withstand the effects of frost and its composition does not show any deformation.

With the conventional track design with a ballast bed, the process of increased wear of the individual grains of gravel begins when the forced oscillation frequency approaches $30 \mathrm{~Hz}$. With an axle distance in the bogie of $2.50 \mathrm{~m}$ and an ideal wheel-rail contact, this situation occurs at a train speed of approx. 270 $\mathrm{km} / \mathrm{h}$. Other factors, such as surface unevenness of the wheel or defects in the rails, also contribute to achieving this frequency. With increasing train speeds and frequencies, increasing vibration amplitudes and higher dynamic stresses, the intervals for maintenance 
of the railway superstructure must be shortened [4]. From the point of view of maintaining the planned operation, maintenance is only possible in regular possession during the night, which can only take a few hours for operational reasons.

Another factor that affects the stress in the railway superstructure is the stiffness of the entire track structure of ballast track construction. The stiffer the construction system, the more the ballast bed is stressed. Especially on bridges and in tunnels, which are abundant on high-speed rails, the stiffness of the system is higher due to the hard base (bridge loadbearing structure, concrete slab in the tunnel) than of the track on earthworks, and thus the ballast bed is significantly more stressed. The lifetime period of the ballast bed is improved or extended by suitable steps, such as the use of transverse sleepers with a larger loading area, a more elastic rail fastening system, the placement of sleepers with under sleeper pads or the placement of sub-ballast vibration damping mats 5 . Experience shows that the adjustment of the track geometry at a line speed above $250 \mathrm{~km} / \mathrm{h}$ must be done after a passing a load of about 100 million gross tons. At DB Netz AG, therefore, since the mid-1990s, a ballastless track has been prescribed for all new constructions as a type of railway track structure, which also applies to all newly built tunnels, regardless of the operating load.

\section{Conclusion}

The economic evaluation of the construction work is a fundamental criterion that decides about its realization, or more precisely about its scope. In this assessment, it is necessary to correctly set the payback period of the investment, which sufficiently considers the lifetime period of the main components of the construction, as well as the costs of maintenance and possession activities. When considering life cycle costs (LCC), investment costs make up only a part of the total costs and it turns out that maintenance costs often far outweigh investment costs.
DB Netz AG's present experience with a ballastless track since its first implementation in Rheda railway station in 1972, for almost 50 years, shows that the required lifetime period of 60 years has its real justification. In addition, current research and development in the field of ballastless track is moving towards extending the lifetime period of ballastless track well beyond this limit.

When assessing the choice of track structure - especially for high-speed rails - it is therefore necessary and correct to assess the total costs (investment and operational) for a sufficiently long time. This number of years should ideally be equal to the value of the least common multiple of the lifetime period of the ballastless track and the lifetime period of the conventional track structure with ballast bed, because in this case the residual value of both variants will be zero at the end of the payback period and in addition, it will be possible to easily include in the total costs the costs of the track removal.

\section{REFERENCES}

[1] SŽDC S9. Pevná jízdní dráha. Praha: Správa železniční dopravní cesty, s. o., 2012, 52 s.

[2] O. Plášek, et al. Železniční stavby: železniční spodek a svršek. Vyd. 1. Brno: CERM, 2004. 291 s. ISBN 80-214-2620-9.

[3] B. Lichtberger. Track compendium: formation, permanent way, maitenance, economics. 1st ed. Hamburk: Eurailpress, @ 2005.634 s. ISBN 3-7771-0320-9.

[4] S. Freudenstein, et al. Feste Fahrbahn in Betonbauweise. BetonKalender 2015. [online]. D-69451 Weinheim, Germany: Wiley-VCH Verlag, 2014, 2015-0123 , pp. 529-584 [cit. 2016-08-31]. ISBN 978-3-4336-03406, https://doi.org/10.1002/9783433603406.ch10.

[5] E. Darr, W. Fiebig. Feste Fahrbahn: Konstruktion und Bauarten für Eisenbahn und Strassenbahn. Hamburg: Eurailpress, (02006. 270 s. ISBN 3-8266-1485-2. 